\title{
Hळ Loop Shaping Based Robust Power System Stabilizer for Three Machine Power Svstem
}

\author{
Dr.J.K.Mendiratta, \\ Professor \\ CMR Institute of technology, Bangalore \\ India
}

\author{
Jayapal R, \\ Assistant Professor \\ R.V.College of Engineering, Bangalore \\ India
}

\begin{abstract}
The dynamics of a multi machine power system are both nonlinear and interconnected. The equilibrium of such a system is typically unknown and uncertain, and the controllers within are also subject to physical limitations. In this paper, application of nonlinear $\mathrm{H} \infty$ robust power system stabilizer design is presented for a three machine system. Based on the latest development of nonlinear $\mathrm{H} \infty$ robust control theory, a control design is applied to stabilize the linearized uncertain system using Glover-McFarlane's loop shaping design procedure for a three machine system. Guidance for setting the feedback configuration for loop shaping and synthesis are presented. The results of simulation studies are presented.
\end{abstract}

\section{Keywords}

closed loop gain, $\mathrm{H} \infty$, loop shaping, linearized model, multi machine, open loop gain, power system stabilizer, robust controller, state space.

\section{INTRODUCTION}

The main objective of installing power system stabilizer (PSS) is to achieve desired stability and security at a reasonable cost by adding damping to electromechanical oscillations. They were developed to extend stability limits by modulating the generator excitation to provide additional damping to the oscillations of synchronous machine rotors. In recent years there has been an increasing interest on applying advanced control designs in power systems like adaptive control, $\mathrm{H} \infty$ control, $\mu$ synthesis, nonlinear control, feedback linearization, fuzzy logic control and neural control have been reported[13]. The goal of these studies is to achieve stability and performance robustness. Conventional stabilizers are not designed in a way to guarantee the desired level of robustness. Such designs are specific for a given operating point; they do not guarantee robustness for a wide range of operating conditions. To include the model uncertainties at the controller design stage, modern robust control methodologies have been used in recent years to design PSS [10]. The resulting PSS ensures the stability for a set of perturbed operating points with respect to the nominal system and has good oscillation damping ability. The proposed control is free from common deficiencies of power system nonlinear controllers as network dependence and equilibrium dependence.

The Ho optimal controller design is relatively simpler in terms of the computational burden. This paper uses the Glover- McFarlane $\mathrm{H} \infty$ loop shaping design procedure [1] to design the PSS. It combines the $\mathrm{H} \infty$ robust stabilization with the classical loop shaping technique. In contrast to the classical loop shaping approach, the loop shaping is done without explicit regard to the nominal plant phase information. The design is both simple and systematic. It does not require an iterative procedure for its solution. In this work, we use this design procedure to PSS design for a three machine, nine bus system and provide some basic guidelines for loop shaping weighting selection and controller design paradigm formulation.

The rest of the paper is organized as follows: In Section II, the power system model description and problem statement are provided. In Section III, the controller design paradigm is given together with detailed simulation results in Section IV; and finally, in Section V conclusions are provided.

\section{POWER SYSTEM MODEL}

To study the control of power system oscillations, three-machine, nine bus system, taken from [8] was used. In this system, the synchronous machine is modeled using Model 1.1[9] in which case one field winding on d-axis and one equivalent damper on qaxis are considered. The relevant equations [9] of model1.1 are provided in Appendix. Each parameter in the equations is a vector or matrix. The system model is created using simulink available in Matlab.

If the PSS design is based on the one machine infinite bus model, after the installations of PSSs on most machines of a large power system, low frequency oscillations may still occur because of the lack of coordination of these stabilizers[12]. Hence coordinated application of PSSs is required. To achieve the coordination, the state matrix of the entire system is used to design PSS using Glover-McFarlane $\mathrm{H} \infty$ loop shaping design procedure. For the system considered this procedure yields three stabilizers one at each machine. Using participation factor technique [16] stabilizers are placed only at the machines where PSS is more essential. For the example considered, the eigen value associated with the two 
swing modes at the given operating point with out PSS are given in Table 1.

\begin{tabular}{|l|l|}
\hline Swing mode & Without PSS \\
\hline M1 & $-0.92893 \pm \mathrm{j} 11.946$ \\
M2 & $-0.2683 \pm \mathrm{j} 7.8228$ \\
\hline
\end{tabular}

Table 1.Eigen values of the system

Table 2 gives the participation factors (magnitude) of the system in modes M1 and M2. The speed of that machine with highest participation in a particular mode is the best signal to damp the oscillations due to that mode.

\begin{tabular}{|l|l|l|l|}
\hline Mode & Sm1 & Sm2 & Sm3 \\
\hline M1 & 0.0047 & 0.0844 & 0.3994 \\
M2 & 0.1387 & 0.3173 & 0.0506 \\
\hline \multicolumn{4}{|c|}{ Table 2 . Participation factors }
\end{tabular}

Hence it can be observed from Table 2 that generator 3 and generatos 2 are the best locations to place PSSs to damp modes M1 and M2 respectively.After obtaining the controller, nonlinear simulations are performed and comparisons of the performances are made with the conventional PSS and the resulting robust stabilizer for three different types of faults.

\section{ROBUST CONTROLLER DESIGN}

The Glover-McFarlane Ho loop shaping design procedure [1, 14] consists of three steps:

\subsection{Loop shaping}

In loop shaping design, the closed-loop performance is specified in terms of requirements on the open-loop singular values. The open loop singular values are then shaped to give desired high or low gain at frequencies of interest. This step takes advantage of the conventional loop shaping technique, but no phase requirements need to be considered. That is, the closed-loop stability requirements are disregarded since the $\mathrm{H} \infty$ synthesis step taken thereafter will robustly stabilize the shaped plant. Using a pre compensator $\mathrm{W}_{1}$ and/or a post compensator $\mathrm{W}_{2}$, the singular values of the nominal plant are shaped to give a desired open-loop shape. $\mathrm{W}_{1}$ is selected to keep the sensitivity $\mathrm{S}=(\mathrm{I}+\mathrm{GK})-1$ low at low frequencies such that $\mathrm{W}_{1}^{-1} \mathrm{~S} \infty \leq 1$, while $\mathrm{W}_{2}$ is selected to keep the complementary sensitivity $\mathrm{T}=\mathrm{GK}(\mathrm{I}+\mathrm{GK})-1$ low at high frequencies such that $\mathrm{W}_{2}^{-1} \mathrm{~T} \infty \leq 1$. This ensures acceptable level of performance as well as stability in the face of perturbations. The nominal plant $G$ and shaping functions $W_{1}, W_{2}$ are combined to form shaped plant, $\mathrm{Gs}=\mathrm{W}_{2} \mathrm{G} \mathrm{W}_{1}$. We assume that $\mathrm{W}_{1}$ and $\mathrm{W}_{2}$ are such that Gs contains no hidden modes.

\subsection{Robust stabilization}

It has been shown that the largest achievable stability margin $\varepsilon$ $\max$, can be obtained by a noniterative method $[4,1]$. $\varepsilon$ max, is the stability margin for the normalized coprime factor robust stability problem[1]. It provides a robust stability guarantee for the closed loop system. Suppose $\overline{\mathrm{M}}_{s}, \overline{\mathrm{N}}_{s}$ are normalized left coprime factors of Gs such that $\mathrm{Gs}=\overline{\mathrm{M}}_{s}^{-1} \overline{\mathrm{N}}_{s}$, then $e_{\max }=\left(1-\left\|\left[\overline{M_{s}} \cdot \overline{N_{s}}\right]\right\|_{\mathrm{H}}^{2}\right)^{1 / 2}$ ... (1) where $\|\cdot\|_{\mathrm{H}}$ denotes the Hankel norm. The controller is now defined by selecting $\varepsilon<=\varepsilon$ $\max$, and then synthesizing a stabilizing controller $\mathrm{K} \infty$, which satisfies

$$
\left\|\left[\begin{array}{l}
\mathrm{I} \\
\mathrm{K}_{\infty}
\end{array}\right]\left(\mathrm{I}-G s \mathrm{~K}_{\infty}\right)^{-1} \overline{\mathrm{M}}_{s}{ }^{-1}\right\|_{\infty} \leq
$$

$\varepsilon-1 \quad$ (See Fig 1a) $\quad\|.\|_{\infty}$ denotes the Ho norm which is the supermum of the largest singular value over all frequencies. If $\varepsilon$ $\max <<1$ return to (1) and adjust $\mathrm{W} 1$ and $\mathrm{W} 2$.

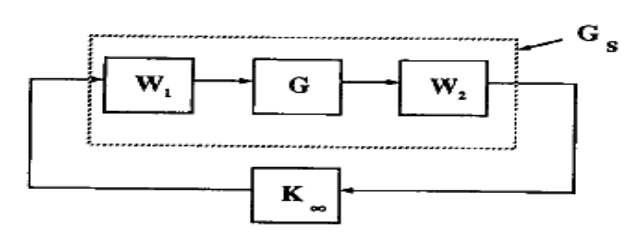

Figure 1a

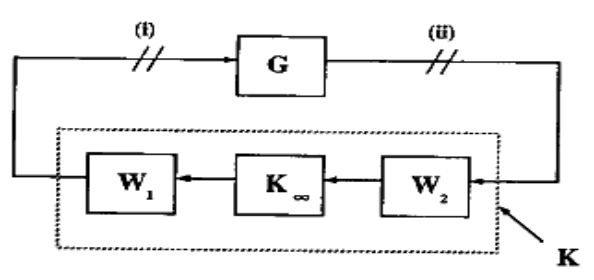

Figure 1b

\subsection{The final feedback controller $K$}

It is then constructed by combining the $\mathrm{H} \infty$ controller $\mathrm{K} \infty$ with the shaping functions $\mathrm{W} 1$ and $\mathrm{W} 2$ such that $\mathrm{K}=\mathrm{W} 1 \mathrm{~K} \infty \mathrm{W} 2$ (see Fig 1b)

\subsubsection{Loop shaping}

The state matrix representation of the system is obtained. The eigen values of this system correspond to the inter-area mode. The damping ratio of the system is computed. The system has poor damping at frequency 7.83 and $12 \mathrm{rad} / \mathrm{sec}$. The objective of loop shaping is to increase the open-loop gain around this frequency [14].

\subsubsection{Selection of $W_{1}$}

We add pole and zero pairs to achieve gain increase in the desired frequency range while keeping the gain change as small as possible around other frequency values [1]. A washout filter block in W1 with time constant 10 s is used to ensure the controller only works in the transient state [14]. The selection of the pole at $1 / 0.5780$ and the zero at 1/0.33 increased the gain around the frequencies of interest so that the plant input disturbance can be attenuated effectively. The resulting transfer function for the weighting W1 is

$\frac{33 * 10^{5} * 10 s *(1+0.33 s)}{(1+10 s)(1+0.5780 s)(1+1.0406)}$




\subsubsection{Selection of $W_{2}$}

With $\mathrm{W}_{2}=1$, the open loop gain $\mathrm{Gs}=\mathrm{W}_{2} \mathrm{G} \mathrm{W}_{1}$ was very less and more over the slope of the shaped plant was low at low frequencies. To increase the gain of the system at low frequency, three repeated zeros are added at 10 . To make $\mathrm{W}_{2}$ proper and to achieve proper slope of Gs at cross over frequency three poles are added at insignificant frequency of 1000 . The reduced dc gain of $\mathrm{W}_{2}$ is compensated by using a constant 26 [14]. The resulting transfer function for the

weighting $\mathrm{W}_{2}$ is $\frac{26 *(s+10)^{3}}{(s+1000)^{3}}$ The resulting singular value plot of nominal system $\mathrm{G}, \mathrm{W}_{1}, \mathrm{~W}_{2}$ and $\mathrm{Gs}$ as shown in Figure 2.

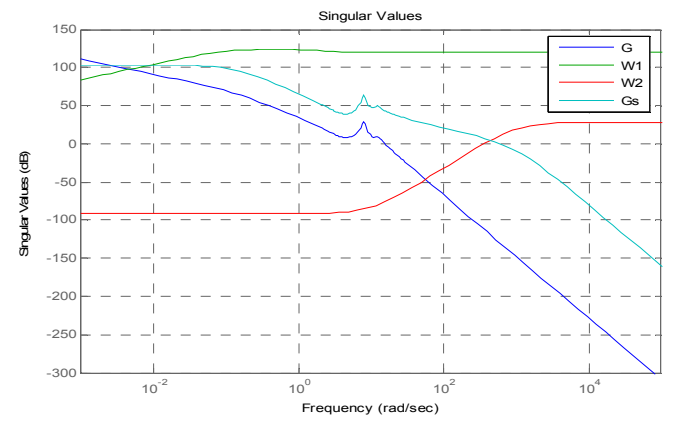

Figure 2 The singular value plot of G, W1, W2 and Gs

\subsubsection{Hळ synthesis}

Next, we synthesized a $\mathrm{K} \infty$ controller to achieve robust stability for the nominal plant. According to (1), the maximum stability margin is $\square \max =0.3868$. This margin evaluates the feasibility of our loop shaping design. According to McFarlane and Glover [3], given the normalized left coprime factorization of the nominal plant as $\mathrm{Gs} 0=\overline{\mathrm{M}} \cdot \mathbf{s}, \overline{\mathrm{N}} s$, the controller $\mathrm{K} \infty$ can stabilize all Gs $=\left(\overline{\mathrm{M}}+\Delta_{\mathrm{M}}\right)^{-1}\left(\overline{\mathrm{N}}+\Delta_{\mathrm{N}}\right) \quad$ satisfying $\left\|\Delta_{\mathrm{M}}, \Delta_{\mathrm{N}}\right\|_{\infty}<0.3868$. This controller stabilizes a gap ball of uncertainty with a given radius if and only if it stabilizes a normalized coprime factor perturbation ball of the same radius. Thus, in terms of the gap metric, all Gs with $\delta g(\mathrm{Gs}, \mathrm{Gs} 0)<$ 0.3868 can be stabilized by this controller.

\subsubsection{The final controller $K$}

The final controller is the combination of W1and W2 with $\mathrm{K} \infty$, that is $\mathrm{K}=\mathrm{W} 1 \mathrm{~K} \infty \mathrm{W} 2$. After adding the designed controller, the damping of the nominal closed-loop system has increased.

\subsubsection{Controller order reduction}

We want to conduct a nonlinear simulation using simulink to examine the performance of the designed controller. The resulting controller has a high order. The controller is reduced to a 7 th order controller using the Hankel Norm reduction. The transfer function of the reduced order controller is given as $\mathrm{Gk}(\mathrm{s})=\mathrm{N}(\mathrm{s}) / \mathrm{D}(\mathrm{s})$, with

$\mathrm{N}(\mathrm{s})=4.677 * 107 \mathrm{~s} 7+7.709 * 1010 \mathrm{~s} 6+4.32 * 1013 \mathrm{~s} 5+$ $5.379 * 1015 \mathrm{~s} 4+1.726 * 1017 \mathrm{~s} 3+2.384 * 1018 \mathrm{~s} 2+2.179 * 1019 \mathrm{~s}+$ $1.199 * 1019$
$\mathrm{D}(\mathrm{s})=\mathrm{s} 7+5625 * \mathrm{~s} 6+1.389 * 107 \mathrm{~s} 5+1.971 * 1010 \mathrm{~s} 4+1.485 * 1013$ $\mathrm{s} 3+5.226 * 1015 \mathrm{~s} 2+4.544 * 1017 \mathrm{~s}+9.129 * 1017$

The bode plots of the full-order controller and the reduced-order controller are shown in Fig. 3.We note that the gain of the controller does not roll off rapidly at high frequencies.

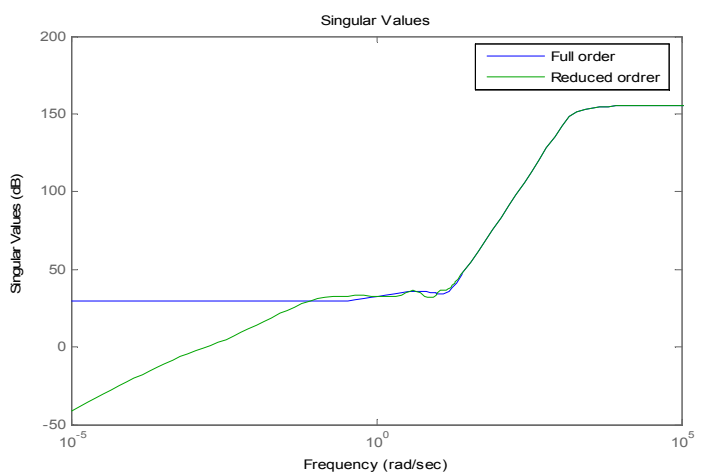

Figure 3a. Bode plot of the actual and reduced order controller

\subsubsection{Convevtional PSS (CPSS)}

The parameters of CPSS [9] are $\mathrm{Tw}=10, \mathrm{Ks}=4, \mathrm{~T} 1=0.1, \mathrm{~T} 2=0.01$, $\mathrm{T} 3=0.0, \mathrm{~T} 4=0.0, \mathrm{Vsmin}=-0.05 \& \mathrm{~V} \operatorname{smax}=0.05$.

\section{SIMULATION RESULTS}

Nonlinear simulations are performed using simulink to test the efficiency of the designed controller. Simulation is carried out by creating three faults namely

1) $10 \%$ increase in Mechanical torque for $0.1 \mathrm{sec}$ followed by restoring the torque back to initial value.

2) $10 \%$ increase in Vref $0.1 \mathrm{sec}$ followed by restoring Vref back to initial value.

3) Three phase fault at the bus bar for $0.1 \mathrm{sec}$

Case 1: $10 \%$ increase in Mechanical torque for $0.1 \mathrm{sec}$ followed by restoring the torque back to initial value. The response is shown only at machine 2 in the following figures although the response at other machines is also similar.

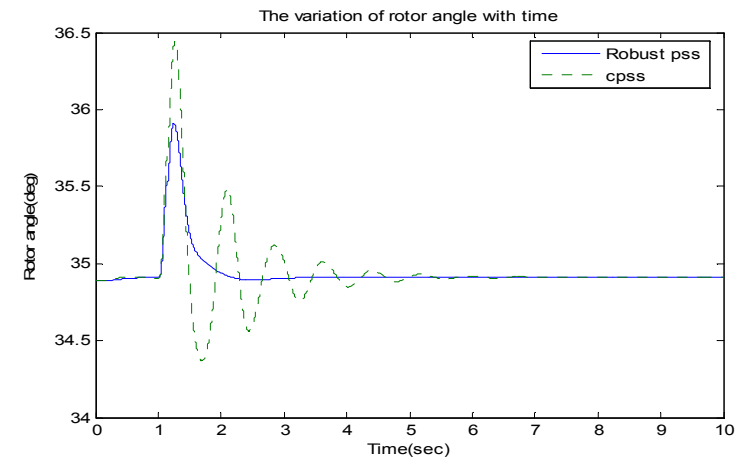

Figure 3 


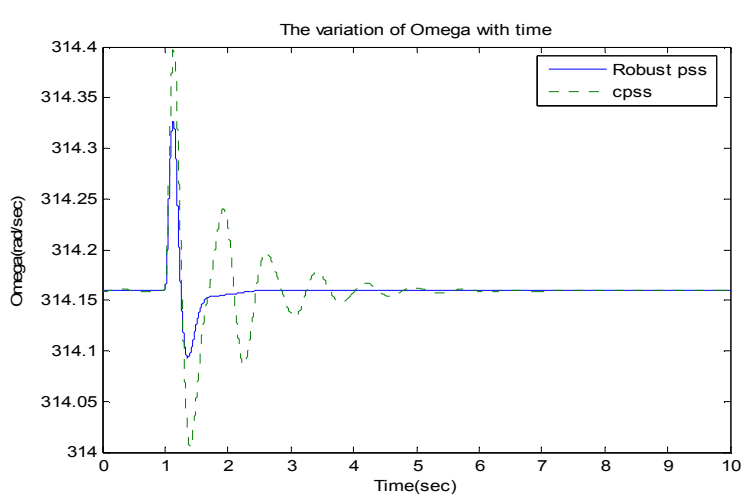

Figure 4

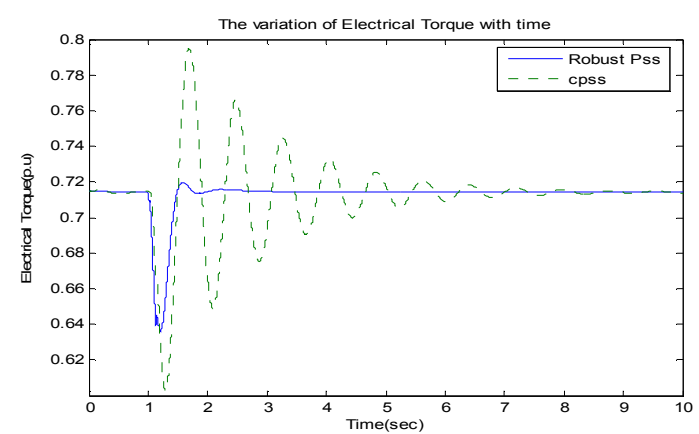

Figure 5

Case2: $10 \%$ increase in Vref for $0.1 \mathrm{sec}$ followed by restoring Vref back to initial value. The response is shown only at machinel in the following figures, though the response is similar at other machines.

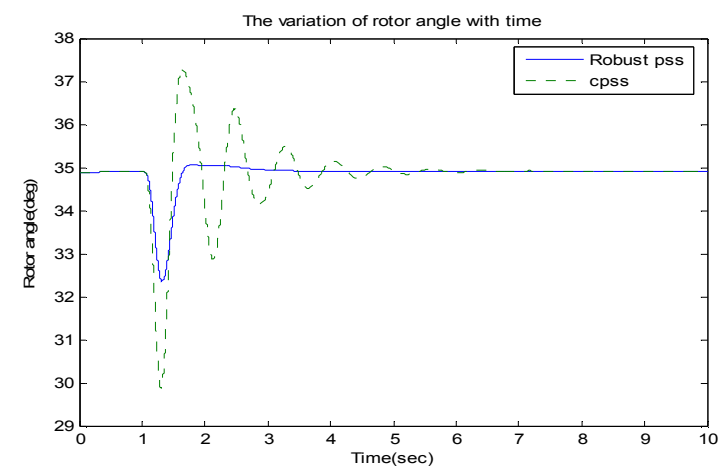

Figure 6

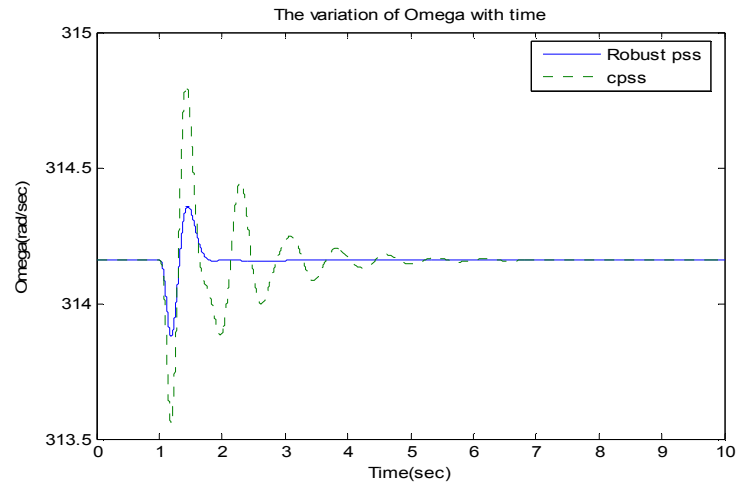

Figure 7

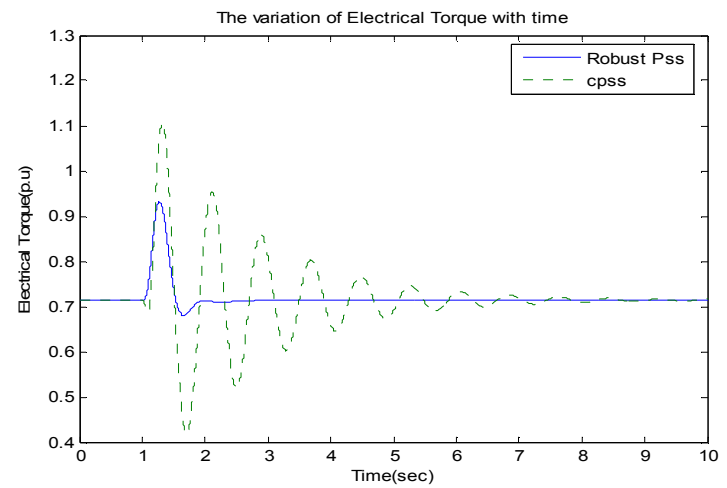

Figure 8

Case3: Three phase fault at bus no.7 for $0.1 \mathrm{sec}$. Again due to want of space response only at machine 3 is shown in the following figures.

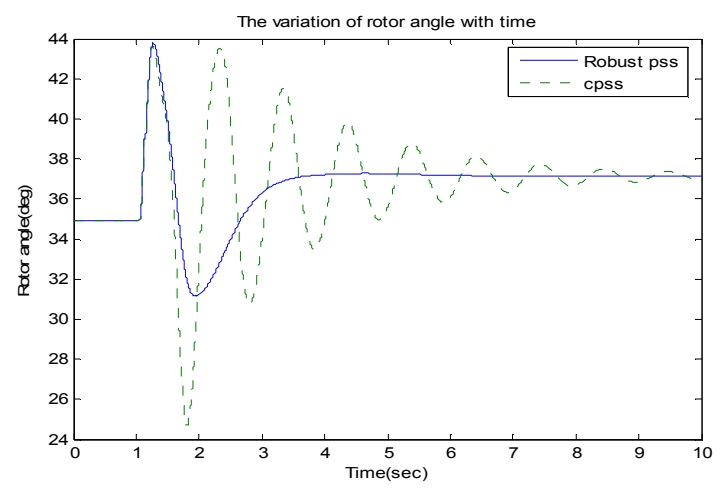

Figure 9 


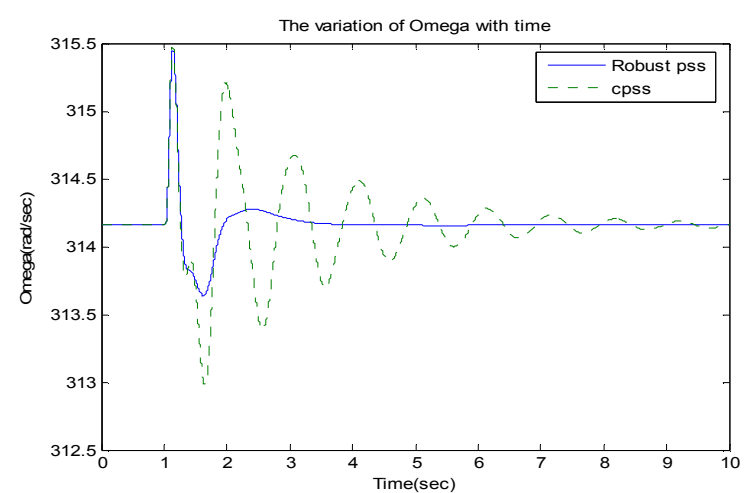

Figure 10

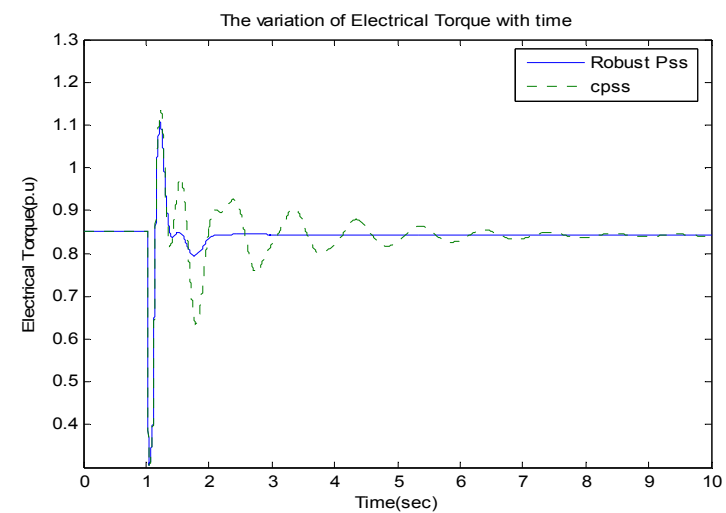

Figure 11

Form fig. 3 to fig. 11 it can be clearly seen that the transients disappear very quickly incase of system with Robust Pss compared to system with Cpss when the system is subjected to different types of disturbances.

Justification of Robustness: For justification of robustness the following three cases are considered.

Case1: Twice the original load A, B\&C. Case2: Five times the original loads $\mathrm{A}, \mathrm{B} \& \mathrm{C}$ and Case3: Eight times the original loads $\mathrm{A}, \mathrm{B} \& \mathrm{C}$. The following figures indicate the response at machine 2 , when the system is subjected to the above three faults.

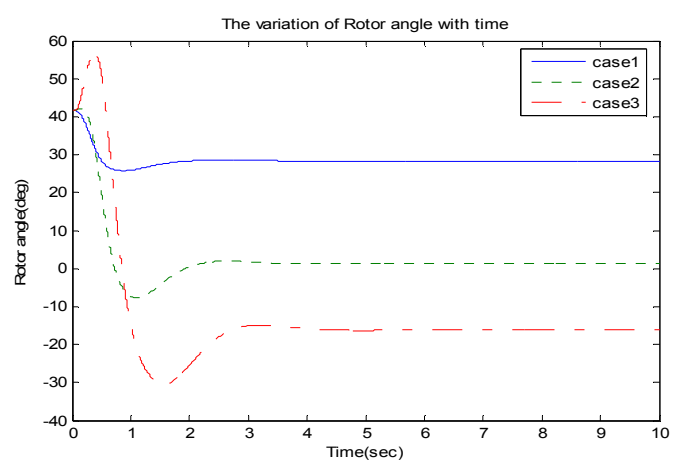

Figure 12

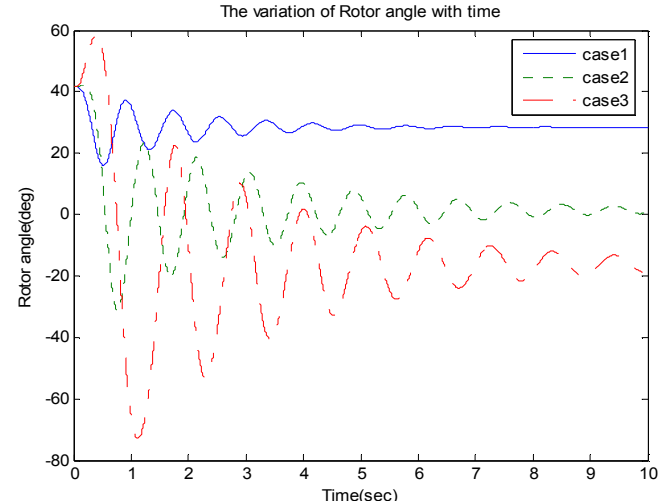

Figure 13

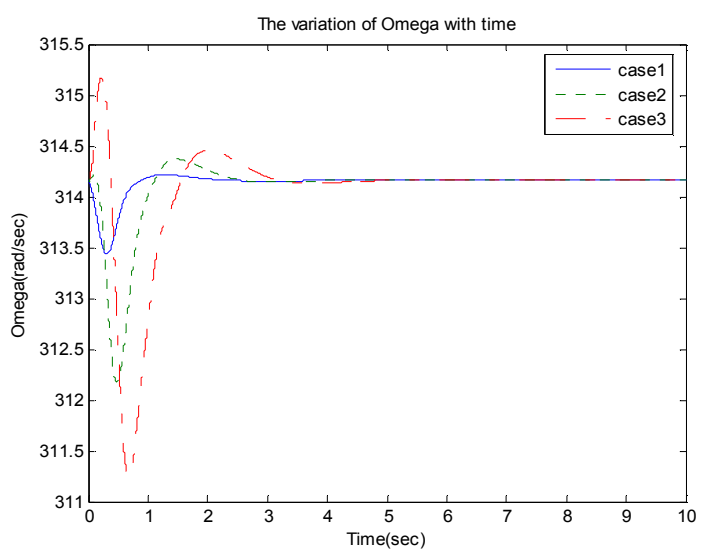

Figure 14

The responses shown in fig12, fig14, fig16 and fig18 correspond to system with Robust Pss while fig13, fig15, fig17 and fig19 correspond to system with Cpss. It can be clearly seen that in case of the system with Robust Pss the settling time is almost independent of the operating point and the system is subjected to low transients contrary to the system operating point and the system is subjected to large transients.

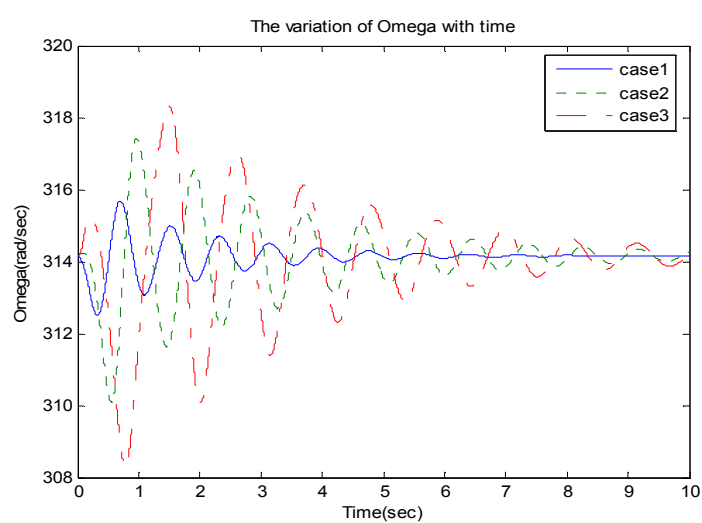

Figure 15 


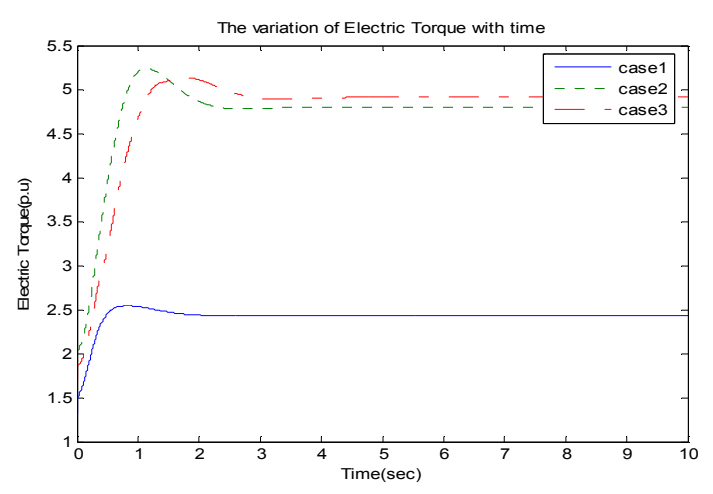

Figure 16

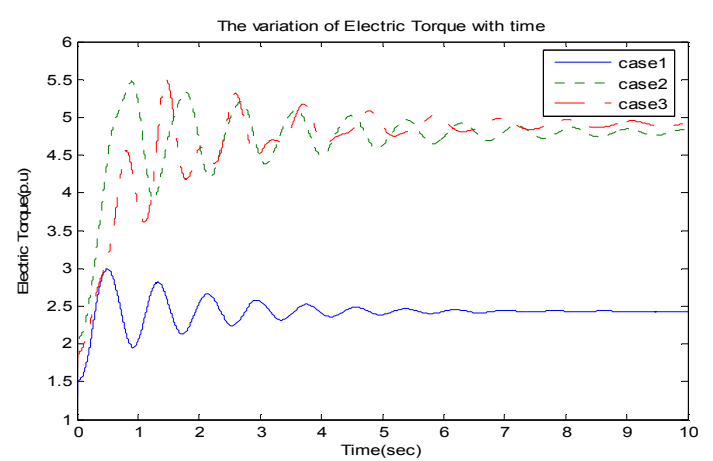

Figure 17

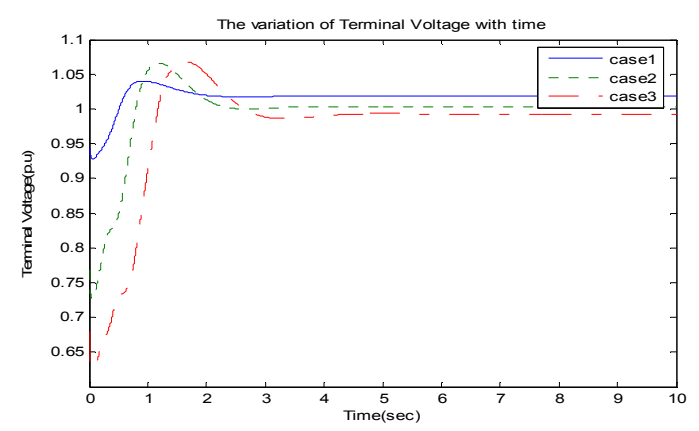

Figure 18

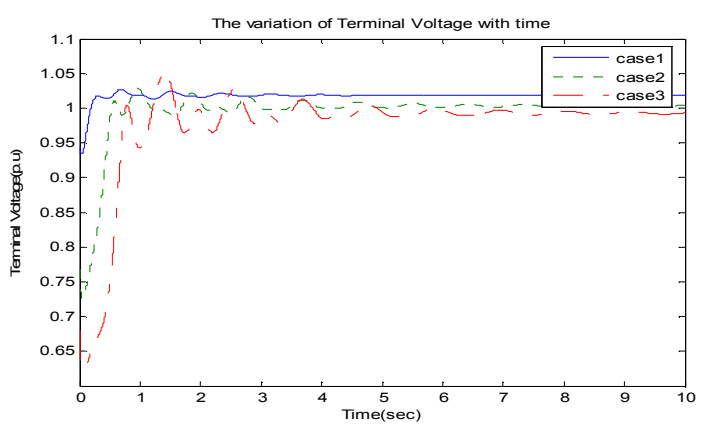

Figure 19

\section{CONCLUSION}

A systematic approach to design PSS using Glover-McFarlane's loop shaping procedure is presented for a three machine system.
The resulting PSS can stabilize the system with perturbations within a gap metric ball with respect to the nominal plant. Simulations demonstrate the good damping performance of the designed controller. $\mathrm{H} \infty$ controller can achieve robustness while the design procedure used is much simpler. The analysis has been used to verify the robustness of the designed controller. Collectively, these results show that the loop shaping controller provides better robustness. The above procedure can be applied to large multimachine / intra-area power system to design the robust controller to take care of the intra-area oscillations under perturbed conditions.

\section{REFERENCES}

[1]. D.C. MacFarlane and K. Glover. A loop shaping design procedure using $\mathrm{H} \infty$ synthesis. AC-37: 759-769, 1992

[2]. J. C. Doyle, B. A. Francis, and A. R. Tannenbaum. Feedback control theory. Macmillan, New York, 1992.

[3]. J.M. Maciejowski, Multivariable feedback design, AddisonWesley publishing company

[4]. J. C. Zhou, J. C. Doyle, and K. Glover. Robust and optimal control. Prentice Hall, New Jersey, 1996.

[5]. Geir E. Dullerud and Fernando Paganini A course in Robust Control Theory, Springer 1999.

[6]. Control Theory: Multivariable and Nonlinear Methods, Tprkel Glad and Lennart Ljung, Taylor and Francis

[7]. Automatic control systems, Benzamin C.kuo, Printice-Hall of India, New Delhi, 2001

[8]. Anderson P.M and Fouad A.A., Power system control and stability, Iowa state university press, Ames, 1977

[9]. Padiyar K.R., power system Dynamics stability and control, second edition, BS publications, 2002.

[10].P. Kundur, Power System Stability and Control. New York: McGraw-Hill, 1993.

[11].Matlab Help Documentation Release 12.

[12].Yao-nan Yu, Electric Power system Dynamics Academic Press 1983.

[13].Dequiang Gan, Zhihu Qu and Hongzhu Cai, Multi machine power system excitation control design via theories of feedback linearization control and nonlinear robust control.

[14].Chuanjiang Zhu, Member, IEEE, Mustafa Khammash, Senior Member, IEEE, Vijay Vittal, Fellow, IEEE, and Wenzheng Qiu, Student Member, IEEE, Robust Power System Stabilizer Design UsingLoop Shaping Approach, IEEE TRANSACTIONS ON POWER SYSTEMS, VOL. 18, NO. 2, MAY 2003

[15].Jayapal.R and Dr.J.K.Mendiratta, Robust power system stabilizer design using $\mathrm{H} \infty$ loop shaping approach for single machine system.

[16].K.R. Padiyar and H.V. Saikumar, Modal Inertia - A New Concept for the Location of PSS in Multimachine Systems, National Systems Conference, Nsc2003.

[17].Bikash Pal and Balarko Chaudhuri, Robust Control in Power Systems, Springer.

\section{APPENDIX}

8.The equations of multimachine system corresponding to Model 1.1 are [9]: 


$$
\text { 9. } \delta_{C O I}=\frac{1}{M_{T}} \sum_{i=1}^{n} M_{i} \delta_{i}
$$

$\omega_{C O I}=\frac{1}{M_{T}} \sum_{i=1}^{n} M_{i} \omega_{i} \frac{d[\delta]}{d t}=\omega_{B}\left[S_{m}\right]=[\omega]-\left[\omega_{o}\right]$

$\left[T_{d o}^{1}\right] \frac{d\left[E_{q}^{1}\right]}{d t}=\left\{-\left[E_{q}^{1}\right]+\left(\left[x_{d}\right]-\left[x_{d}^{1}\right]\left[i_{d}\right]+\left[E_{f d}\right]\right\}\right.$

$\left[T_{q o}^{1}\right] \frac{d\left[E_{d}^{1}\right]}{d t}=\left\{-\left[E_{d}^{1}\right]-\left(\left[x_{q}\right]-\left[x_{q}^{1}\right]\right)\left[i_{q}\right]\right\}$

10.

$$
\left[T_{c}^{1}\right] \frac{d\left[E_{d c}^{1}\right]}{d t}=\left\{\left(\left[x_{d}^{1}\right]-\left[x_{q}^{1}\right]\right)\left[i_{q}\right]-\left[E_{d c}^{1}\right]\right\}
$$

$\left[T_{a}\right] \frac{d\left[E_{f d}\right]}{d t}=\left[\left[K_{a}\right]\left[\left[V_{r e f}\right]+\left[V_{S}\right]-\left[V_{t}\right]\right)-\left[E_{f d}\right]\right]$

$\left[\begin{array}{l}{\left[i_{d}\right]} \\ {\left[i_{q}\right]}\end{array}\right]=\left[\begin{array}{cc}{\left[R_{a}\right]} & {\left[x_{q}^{1}\right]} \\ -\left[x_{d}^{1}\right] & {\left[R_{a}\right]}\end{array}\right]^{-1}\left[\begin{array}{l}{\left[E_{d}^{1}\right]-\left[v_{d}\right]} \\ {\left[E_{q}^{1}\right]-\left[v_{q}\right]}\end{array}\right]$

$\left[\begin{array}{l}V_{D} \\ V_{Q}\end{array}\right]=\left[\begin{array}{cc}Z_{R} & Z_{I} \\ -Z_{I} & Z_{R}\end{array}\right]\left[\begin{array}{l}I_{D} \\ I_{Q}\end{array}\right]$

11. $T_{e i}=E_{d i}^{1} i_{d i}+E_{q i}^{1} i_{q i}+\left(x_{d i}^{1}-x_{q i}^{1}\right) i_{d i} i_{q i}$

$\hat{I}_{g}=Y_{g}\left[E_{q}^{1}+j\left(E_{d}^{1}+E_{d c}^{1}\right)\right] e^{j \delta} \quad$ and $\quad Y_{g}=\frac{1}{R_{a}+j x_{d}^{1}}$

where $\left[Z_{R}+j Z_{I}\right]=[Z]=[Y]^{-1}$ and $[Y]$ is the complex admittance matrix which is obtained by augmenting the bus admittance matrix $\mathrm{YN}$ by shunt admittance $\mathrm{Yg}$ of generator and load admittances at the generator and load buses Yl

\subsection{The Data}

This section lists the data [8] used for the Machines, Excitation system and Load along with Impedance diagram.

\begin{tabular}{|l|l|l|l|}
\hline Generator & 1 & 2 & 3 \\
\hline Rated MVA & 247.5 & 192 & 128 \\
\hline KV & 16.5 & 18 & 13.8 \\
\hline pf & 1 & 0.85 & 0.85 \\
\hline Type & hydro & steam & steam \\
\hline Speed, rpm & 180 & 3600 & 3600 \\
\hline $\mathrm{x}_{\mathrm{d}}$ & 0.146 & 0.8958 & 1.3125 \\
\hline $\mathrm{x}_{\mathrm{d}}{ }^{\prime}$ & 0.0608 & 0.1198 & 0.1813 \\
\hline $\mathrm{x}_{\mathrm{q}}$ & 0.0969 & 0.8645 & 1.2578 \\
\hline $\mathrm{x}_{\mathrm{q}}{ }^{\prime}$ & 0.0969 & 0.1969 & 0.2500 \\
\hline
\end{tabular}

\begin{tabular}{|l|l|l|l|}
\hline $\mathrm{t}^{\prime}{ }_{\mathrm{do}}$ & 8.9600 & 6.0000 & 5.8900 \\
\hline $\mathrm{t}_{\mathrm{q} \mathrm{o}}$ & 0 & 0.535 & 0.6 \\
\hline $\mathrm{Ka}$ & 100 & 100 & 100 \\
\hline $\mathrm{Ta}$ & 0.05 & 0.05 & 0.05 \\
\hline
\end{tabular}

Load A: 125.0-j50.0MVA,

Load B: 90.0-j30.0MVA,

Load C: 100.0-j30.0MVA. 
...Blank Page..

..Blank Page.

Blank Page 